\title{
Toward earlier identification and preventative intervention in schizophrenia: evidence from the London Child Health and Development Study
}

\author{
Kristin R. Laurens ${ }^{1,3,4} \cdot$ Alexis E. Cullen ${ }^{1,2}$
}

Received: 1 September 2015/Accepted: 8 November 2015/Published online: 15 December 2015

(C) The Author(s) 2015. This article is published with open access at Springerlink.com

\begin{abstract}
Purpose The London Child Health and Development Study (CHADS) is a prospective, longitudinal investigation of children, sampled from the general community aged 9-11 years and assessed biennially, who present premorbid risk markers for schizophrenia. The study aims to characterise developmental trajectories of psychological, cognitive, and biological functioning in atrisk children and identify potential targets for early preventative intervention. This review summarises CHADS findings, discusses these in the context of recent theory regarding aetiology and prevention of schizophrenia, and highlights challenges to be addressed with future research.

Methods We review (1) epidemiological information on the prevalence and correlates of developmental antecedents of schizophrenia in the general child population, (2) evidence of psychosocial, cognitive, and biological dysfunctions in at-risk children presenting
\end{abstract}

Kristin R. Laurens

Kristin.Laurens@kcl.ac.uk; Kristin.Laurens@unsw.edu.au

1 Department of Forensic and Neurodevelopmental Sciences, Institute of Psychiatry, Psychology \& Neuroscience, King's College London, London, UK

2 Health Service and Population Research Department, Institute of Psychiatry, Psychology \& Neuroscience, King's College London, London, UK

3 Research Unit for Schizophrenia Epidemiology, School of Psychiatry, University of New South Wales, Sydney, Australia

4 Schizophrenia Research Institute, Sydney, Australia multiple antecedents of schizophrenia and at-risk children with a family history of schizophrenia, and (3) related findings from an associated sample of helpseeking children receiving intervention.

Results Community-based screening of 9-11-year olds identified $\sim 9 \%$ with a triad of antecedents of schizophrenia [including psychotic-like experiences (PLEs)] who are putatively at-risk of psychosis; these children reported greater exposure and responsivity to stressors, impairments in general intelligence and specific cognitive functions, brain structure and function abnormalities, and neuromotor dysfunction. Preliminary evidence suggests distressing PLEs are a viable target for cognitive-behavioural intervention in at-risk children.

Conclusions Intervention in early, premorbid phases of illness might alleviate current difficulties and avert future schizophrenia using benign treatments. The CHADS programme has identified several markers that may index early pathophysiology and constitute potential targets for preventative intervention.

Keywords Psychosis - High-risk · Developmental psychopathology · Psychotic-like experiences .

Adolescence

\section{Introduction}

Over the past two decades, considerable research and clinical effort has been invested in devising methods of early detection and intervention for psychosis, with the aims of delaying, ameliorating, and ultimately preventing, illness onset [1]. This work has focussed predominantly on the identification and treatment of symptomatic, helpseeking individuals purportedly experiencing the 
prodromal phase of illness that immediately precedes the onset of frank psychosis, typically during later adolescence or early adulthood. Within 2-3 years of presentation, a third of these "clinically high risk (CHR) ${ }^{1}$ " individuals transition to psychotic illness [2]; a substantial proportion continue to experience persistent psychopathology, marked psychosocial impairment, and compromised quality of life; and only a third experience clinical remission [3]. This trajectory of persisting or worsening functional disability for the majority underscores a need for earlier intervention. That is, preventing psychosis and associated adverse outcomes might be more effective if we could identify at-risk individuals in the premorbid phase of illness, prior to the advent of the significant disability that characterises the prodrome, and without restriction to those accessing health services. Motivated by this aspiration, the London Child Health and Development Study (CHADS) was designed as a prospective, longitudinal, observational investigation of a cohort of children sampled from the general community at age 9-11 years, and enriched with individuals putatively at high risk for developing schizophrenia and the spectrum disorders (SSD). The primary goal of the study was to characterise developmental trajectories of at-risk individuals through adolescence and into young adulthood, with the aim of determining markers of evolving disease that, in the longer term, might be targeted with early, preventative interventions.

Established methods for the identification of individuals potentially experiencing the psychosis prodrome are based on clinical assessment of help-seeking individuals. $^{2}$ Our research required a new method for prospectively identifying at-risk children in the premorbid phase of illness via screening of the general population. Although family history of schizophrenia represents the most established of risk markers for the illness ( $\sim 10-15 \%$ of individuals with a first-degree relative with schizophrenia develop the disorder), a lack of family history for the majority with schizophrenia [6] renders this a limited means of identifying at-risk individuals in the population. During 2004-2005, we therefore piloted a novel method of screening community samples in the United Kingdom (UK), using self- and caregiver-report questionnaires [7], to identify putatively

\footnotetext{
1 The CHR state is also known as the "at-risk mental state" (ARMS) and "ultra-high-risk" (UHR) state [1].

${ }^{2}$ Established methods (reviewed in [1]) for the identification of individuals in this prodromal phase include the complementary UHR [4] and basic symptoms [5] criteria assessed via clinical interview, with the latter possibly identifying an earlier phase of the prodromal state than UHR criteria.
}

at-risk children who presented multiple, replicated, developmental antecedents of schizophrenia. These antecedents, identified in previous prospective longitudinal investigations as distinguishing children who later developed SSD from those who did not [8-10], are thought to represent early manifestations of the disease pathology (compared to "risk factors", which may be conceptualised as more passive markers of increased risk). As these antecedents are not specific for SSD relative to other adult psychiatric disorders (albeit their association with SSD is typically of greater relative magnitude), we reasoned that a combination of antecedents would identify putatively at-risk children with greater sensitivity and specificity than any single antecedent. Our brief questionnaire provided a cost-effective means of screening large numbers of children in the general population for the antecedents within a primary school setting, with sampling restricted to children aged 9 years and older so as to obtain reliable and valid selfreports. As some of the strongest and/or most replicated antecedents of SSD identified in systematic reviews [810] are not amenable to accurate assessment via questionnaire (e.g. obstetric complications, premorbid intellectual [IQ] deficits), our questionnaire incorporated antecedents that were strongly associated with later schizophrenia and suited to questionnaire assessment. ${ }^{3}$ We additionally assessed family history of mental health problems (including SSD).

Within the CHADS programme, children completing questionnaire screening provided a community sample (cross-sectional data) from which several longitudinal cohorts were convened, including (1) an unselected community sample of children who have been assessed sporadically using questionnaires and interviews, and (2) a selected sample of children who have completed detailed laboratory-based assessments biennially. This review summarises CHADS findings published to date, including epidemiological findings (from the community cohorts) and psychological, cognitive, and neurobiological findings (from the selected longitudinal cohort), as well as findings

\footnotetext{
${ }^{3}$ Items assessed psychotic-like experiences (child- and caregiverreport), internalising and externalising psychopathology (emotional symptoms, peer relationship problems, conduct problems, and hyperactivity-inattention; child- and caregiver-report using the Strengths and Difficulties Questionnaire [11, 12]), and delays or abnormalities in speech and/or motor milestone development (caregiver-report). Additional items assessed family history of mental health problems including SSD (caregiver-report), and demographic items (child- and caregiver-report). See Table 2 (screening phase) for further detail.
} 
Table 1 Summary of CHADS programme cohort characteristics (pilot, community, selected, and associated intervention cohorts) and associated publications

\begin{tabular}{|c|c|c|}
\hline CHADS cohort & Sample characteristics & $\begin{array}{l}\text { Associated } \\
\text { publications }\end{array}$ \\
\hline $\begin{array}{l}\text { 1. Pilot study sample } \\
\text { (2004-2005) }\end{array}$ & $\begin{array}{l}548 \text { children aged } 9-11 \text { years (mean age } 10.6 \text { years; } 54.7 \% \text { female) and } 264 \\
\text { primary caregivers, comprising: } \\
129 \text { children and caregivers who completed questionnaires via General Practitioner } \\
\text { surgeries ( } 21.6 \% \text { of } 597 \text { children enrolled at collaborating surgeries) } \\
421 \text { children ( } 97.7 \% \text { of children eligible) who completed questionnaires in school } \\
\text { class and } 136 \text { caregivers }(32.3 \%)\end{array}$ & [7] \\
\hline $\begin{array}{l}\text { 2a. Community sample } \\
\text { (screening) }\end{array}$ & $\begin{array}{l}7966 \text { children completing questionnaires anonymously in school class (94.6\% of } \\
\text { children eligible; mean age } 10.4 \text { years; } 49.2 \% \text { female) and } 1504 \text { primary } \\
\text { caregivers }(18.9 \%)\end{array}$ & $\begin{array}{l}{[9,17,85] \text { (subset of }} \\
\text { sample); [15] }\end{array}$ \\
\hline $\begin{array}{l}\text { 2b. Longitudinal community } \\
\text { sample }\end{array}$ & $\begin{array}{l}670 \text { children and caregivers (mean age } 10.3 \text { years; } 53.4 \% \text { female) - the subset of } \\
799 \text { families who provided identities and contact information at screening and } \\
\text { whose contact information remained valid at first reassessment approximately } \\
2 \text { years later }\end{array}$ & {$[27,28,73]$} \\
\hline $\begin{array}{l}\text { 3. Longitudinal selected sample } \\
\text { (biennial assessments) }\end{array}$ & $\begin{array}{l}111 \text { children and caregivers, comprising: } \\
46 \text { TD; } 33 \mathrm{ASz} \text {; } 26 \mathrm{FHx} \text {; and } 6 \text { children meeting both ASz and FHx criteria }{ }^{\mathrm{a}} \\
\text { Biennial assessments completed at ages } 9-12 \text { years (baseline); 11-14 years (follow- } \\
\text { up 1); } 13-16 \text { years (follow-up 2); and } 17-18 \text { years (follow-up 3) } \\
\text { (Note: a further } 39 \text { children with alternative illness risk profiles, including bipolar } \\
\text { disorder, were recruited in insufficient numbers to provide viable groups for } \\
\text { examination) }\end{array}$ & $\begin{array}{l}{[30,34,35,39,43,48,} \\
\quad 52,53,55,56]\end{array}$ \\
\hline \multirow[t]{2}{*}{$\begin{array}{l}\text { 4. CHADS-associated } \\
\text { intervention samples }\end{array}$} & $\begin{array}{l}\text { Clinical case series: four children from the community sample who completed a } \\
\text { new, manualised cognitive behavioural intervention for children presenting } \\
\text { psychotic-like experiences and emotional distress }\end{array}$ & {$[74]$} \\
\hline & $\begin{array}{l}\text { Coping with unusual experiences for children study (CUES): doi 10.1186/ } \\
\text { ISRCTN13766770 (Lead: Dr. S. Jolley)-for children aged 8-14 years presenting } \\
\text { to Child and Adolescent Mental Health Services with unusual experiences and } \\
\text { emotional distress } \\
\text { Coping with unusual experiences for 12-18 (CUES+): doi } 10.1186 / \\
\text { ISRCTN21802136 (Lead: Dr. S. Jolley)-for users of adolescent community } \\
\text { mental health services (aged 12-18 years) who report distressing unusual } \\
\text { experiences }\end{array}$ & {$[75-78]$} \\
\hline
\end{tabular}

CHADS London Child Health and Development Study, TD typically developing children, $A S z$ children presenting a triad of developmental antecedents of schizophrenia, $F H x$ children with a family history of schizophrenia/schizoaffective disorder

${ }^{a}$ Includes eight FHx children recruited via contact with patients receiving treatment in the local health service rather than via school screening

from an associated sample of help-seeking children receiving intervention, discusses these findings in the context of recent theory regarding aetiology and prevention of SSD, and outlines challenges remaining for future research.

\section{Methods}

Table 1 summarises the community and selected cohorts incorporated within the CHADS programme and their associated publications. 


\section{Community (cross-sectional and longitudinal) cohorts}

Our sampling and recruitment strategies are detailed elsewhere [7, 9]. Briefly, during 2005-2010, children aged 9-11 years were sampled from 73 collaborating primary schools within Greater London. ${ }^{4}$ Children $(n=7966$; $95 \%$ of eligible children) completed questionnaires independently and anonymously in class, with items read aloud by a researcher. Caregivers completed corresponding questionnaires (matched by code) at home and returned them via reply-paid mail $(n=1504)$; this constituted the cross-sectional community sample [Table 1, “2a. Community sample (screening)"].

Caregivers were invited to provide child and caregiver identities and contact information, indicating their willingness to consider further research participation ( $n=799$ families). A longitudinal community sub-cohort (Table 1, "2b. Longitudinal community sample") was derived from the screening sample and assessed for representativeness, ${ }^{5}$ with sampling weights applied in analyses where appropriate.

\section{Selected longitudinal cohort}

From the screening questionnaires, a triad of antecedents of schizophrenia (ASz) were defined to include: (1) child-reported subclinical psychotic symptoms [or psychotic-like experiences (PLEs)], (2) child-reported emotional symptoms and/or caregiver-reported behavioural or social problems, and

\footnotetext{
${ }^{4}$ Collaborating schools spanned the range of socio-economic disadvantage represented in London schools (as indexed by eligibility of children to receive free school meals; with oversampling of deprived inner-London communities) and included state and religious schools of variable enrolment size. Eighty percent of children attended school within the inner-city London Boroughs of Lambeth* $(35.1 \%)$, Southwark* $(22.1 \%)$, Lewisham* $(18.6 \%)$, Tower Hamlets* $(2.6 \%)$, and Westminster $(1.6 \%)$, with the remaining fifth sampled from the outer London Boroughs of Croydon $(8.5 \%)$, Bromley (7.0\%), Brent* (3.2\%), and Harrow (1.4\%). Boroughs indicated by * are among the most deprived $10 \%$ of all English local authorities according to the Index of Multiple Deprivation 2010 [13] and the lowest scoring $10 \%$ on the Local Index of Child Well-Being [14]. School-level data obtained from the Office for National Statistics at the time of sampling indexed the socio-economic status and ethnic diversity of the sample: On average, $31.2 \%$ of children in participating schools were eligible to receive free school meals (range 1.9-62.2 \%; cf. Greater London average $25.3 \%$, and England average $15.8 \%$ ); $24.9 \%$ of children were of white British ethnicity (range $0-80.8 \%$; cf. Greater London average $37.1 \%$, and England average $80.3 \%$ ), with the remainder of black (45.2\%), Asian $(11.4 \%)$, other white $(9.0 \%)$, or other $(9.5 \%)$ ethnicities.

5 Representative indices (by child self-report) include basic demographic information (age, sex), PLEs [7, 15], and emotional symptoms, peer relationship problems, conduct problems, and hyperactivity-inattention $[11,12]$. Few differences between the cross-sectional and longitudinal community samples are notable on these measures (see primary publications and [9]).
}

(3) caregiver-reported delays or abnormalities in speech and/ or motor development $[7,9]$. Three groups of children were recruited from the community screening sample and followed with biennial assessments that measured psychological, cognitive, and biological features previously shown to be characteristic features of adults with schizophrenia, forming a longitudinal selected sample of 111 children (Table 1, "3. Longitudinal selected sample (biennial assessments)"). The groups incorporated two high risk groups, namely children presenting the antecedent triad (ASz group) and children with a family history (in first- or second-degree relatives) of schizophrenia or schizoaffective disorder (FHx group), as well as a group of low risk, typically developing children who presented no antecedents or family history of schizophrenia (TD group). Table 2 details the measures included in the five assessment phases conducted to date in this selected cohort. ${ }^{6}$

\section{Related intervention cohorts}

We additionally summarise findings obtained to date from CHADS-associated intervention research with help-seeking children (Table 1, "4. CHADS-associated intervention samples"); that is, children identified through mental health services and not community screening.

\section{Results}

\section{Epidemiological findings}

Data from our CHADS cross-sectional and longitudinal community sampling have provided important epidemiological information concerning the prevalence and correlates of developmental antecedents of schizophrenia in the general child population, particularly PLEs.

\section{Developmental antecedents of SSD}

Consistent with the elevated incidence of schizophrenia in the London community from which our sample was drawn [16], more than three quarters of children aged 9-11 years experienced at least one of the antecedents within the triad (Fig. 1), with just under a tenth $(9.4 \%)$ presenting all three. Caregiver reports of a family history of

\footnotetext{
${ }^{6}$ Assessment phases in the longitudinal selected sample include: screening (9-11 years), baseline (9-12 years), and first (11-14 years), second (13-16 years), and third follow-up (17-18 years). Measures that were assessed more widely, in the longitudinal community sample, are indicated in Table 2 using the symbol "+". The initial questionnaire assessment which provided cross-sectional data in the community sample (from which the longitudinal community sample and longitudinal selected samples were derived) is summarised under the screening phase.
} 
Table 2 Summary of the assessments completed with the longitudinal selected sample at each assessment phase

\begin{tabular}{|c|c|c|c|c|c|c|c|}
\hline \multirow[t]{2}{*}{ Domain } & \multirow{2}{*}{$\begin{array}{l}\text { Assessment method } \\
\text { (informant) }\end{array}$} & \multirow{2}{*}{$\begin{array}{l}\text { Assessment } \\
\text { instrument }\end{array}$} & \multicolumn{5}{|c|}{ Assessment phase } \\
\hline & & & SCR & $\mathrm{BL}$ & FU1 & FU2 & $\mathrm{FU}^{\mathrm{a}}$ \\
\hline \multicolumn{8}{|l|}{ Psychopathology } \\
\hline $\begin{array}{l}\text { Social, emotional, and } \\
\text { behavioural problems }\end{array}$ & $\begin{array}{l}\text { Questionnaire }(\mathrm{P}, \mathrm{C} \text {, } \\
\mathrm{T})\end{array}$ & $\begin{array}{l}\text { Strengths and Difficulties Questionnaire (SDQ }[11,12,86]) \text { : } \\
\text { psychopathology scales (emotional symptoms, peer } \\
\text { relationship problems, conduct problems, hyperactivity- } \\
\text { inattention), prosocial behaviour scale, and supplement } \\
\text { assessing impact of psychopathology }\end{array}$ & $\checkmark$ & $\checkmark$ & $\boldsymbol{\nu}^{+}$ & $\checkmark$ & $\checkmark$ \\
\hline \multirow[t]{2}{*}{$\begin{array}{l}\text { DSM-IV diagnoses and } \\
\text { symptoms (including } \\
\text { psychotic symptoms) }\end{array}$} & Interview $(\mathrm{P}, \mathrm{C})$ & $\begin{array}{l}\text { Kiddie Schedule for Affective Disorders and Schizophrenia- } \\
\text { Present and Lifetime version (K-SADS-PL) [87] [primary } \\
\text { caregiver: full schedule; child: anxiety and psychotic } \\
\text { symptoms (screening and supplement) questions only] }\end{array}$ & - & $\checkmark$ & - & - & - \\
\hline & $\begin{array}{l}\text { Questionnaire }(\mathrm{P}, \mathrm{C}, \\
\quad \& \mathrm{~T})\end{array}$ & $\begin{array}{l}\text { Achenbach System of Empirically Based Assessment } \\
\text { (ASEBA [88]): Child Behavior Checklist (CBCL), Youth } \\
\text { Self-Report (YSR), Teacher Report Form (TRF) }\end{array}$ & - & $\checkmark$ & $\boldsymbol{r}$ & $\boldsymbol{v}$ & $\checkmark$ \\
\hline Anxiety symptoms & Questionnaire (C) & $\begin{array}{l}\text { Revised Child Manifest Anxiety Scale, second edition } \\
\text { (RCMAS-2 [89]) }\end{array}$ & - & $\boldsymbol{V}$ & $\checkmark$ & $\checkmark$ & - \\
\hline Depressive symptoms & Questionnaire (C) & Beck Depression Inventory for Youth (BDI-Y [90]) & - & $\checkmark$ & $\boldsymbol{V}$ & $\boldsymbol{v}$ & - \\
\hline Antisocial traits & Questionnaire $(\mathrm{P}, \mathrm{C})$ & Antisocial Process Screening Device [91] & - & $\checkmark$ & $\boldsymbol{V}$ & $\boldsymbol{V}$ & - \\
\hline Autistic symptoms & Questionnaire (P) & Social Communication Questionnaire—-lifetime version [92] & - & $\checkmark$ & - & - & - \\
\hline Psychotic-like experiences & Questionnaire $(\mathrm{P}, \mathrm{C})$ & $\begin{array}{l}\text { Psychotic-Like Experiences (PLE) Questionnaire }[7,15] \text { : } \\
\text { items assessing hallucination- and delusion-like experiences, } \\
\text { and associated impact }\end{array}$ & $\boldsymbol{v}$ & $\checkmark$ & $\boldsymbol{\sigma}^{+}$ & $\checkmark$ & $\checkmark$ \\
\hline $\begin{array}{l}\text { Prodromal symptoms of } \\
\text { psychosis }\end{array}$ & Questionnaire (C) & Prodromal Questionnaire [93] & - & - & - & $\boldsymbol{\sim}$ & $\checkmark$ \\
\hline Psychotic symptoms & Interview $(\mathrm{C})$ & $\begin{array}{l}\text { Comprehensive Assessment of At-Risk Mental State } \\
\text { (CAARMS [94]) }\end{array}$ & - & - & - & - & $\checkmark$ \\
\hline Personality & Questionnaire (P) & Big Five Inventory [95] adapted for Children & - & - & - & $\boldsymbol{V}$ & - \\
\hline Global functioning & Interview $(\mathrm{C})$ & Global Assessment of Functioning scale (GAF [96]) & - & $\checkmark$ & - & - & $\checkmark$ \\
\hline \multicolumn{8}{|c|}{ Medical and developmental history } \\
\hline Developmental delays & Questionnaire (P) & $\begin{array}{l}\text { Items assessing delays/problems in the attainment of speech or } \\
\text { motor milestones [7] }\end{array}$ & $\boldsymbol{v}$ & - & - & - & - \\
\hline $\begin{array}{l}\text { Medical and psychiatric } \\
\text { history }\end{array}$ & Interview $(\mathrm{C})$ & $\begin{array}{l}\text { Family Interview for Genetic Studies (FIGS [97]) to identify } \\
\text { known medical and psychiatric conditions in the child and } \\
\text { other family members }\end{array}$ & - & $\checkmark$ & $\checkmark$ & $\boldsymbol{V}$ & - \\
\hline \multicolumn{8}{|l|}{ Relationships assessment } \\
\hline Parenting practices & Questionnaire $(\mathrm{P}, \mathrm{C})$ & Alabama Parenting Questionnaire [98] & - & $\checkmark$ & $\boldsymbol{V}$ & $\boldsymbol{V}$ & - \\
\hline Family functioning & Questionnaire (P) & McMaster Family Assessment Device [99] & - & - & - & $\checkmark$ & - \\
\hline Expressed emotion & $\begin{array}{l}\text { Standardised rating } \\
(\mathrm{P})\end{array}$ & $\begin{array}{l}\text { Expressed emotion rating scale (coded from video recording) } \\
{[100,101]}\end{array}$ & - & $\checkmark$ & $\boldsymbol{v}$ & $\checkmark$ & - \\
\hline \multicolumn{8}{|l|}{ Child experiences } \\
\hline Alcohol and drug use & Questionnaire (C) & $\begin{array}{l}\text { Adapted version of the Edinburgh Study of Youth Transitions } \\
\text { and Crime alcohol and drug use questionnaires [102] }\end{array}$ & - & $\checkmark$ & $\checkmark$ & $\checkmark$ & $\checkmark$ \\
\hline $\begin{array}{l}\text { Daily hassles and life } \\
\text { events }\end{array}$ & Questionnaire (C) & $\begin{array}{l}\text { Adapted version of a daily school-related hassles and negative } \\
\text { life events questionnaire [103] }\end{array}$ & - & $\checkmark$ & $\checkmark$ & $\checkmark$ & - \\
\hline Threatening life events & Questionnaire (C) & List of Threatening Events (LTE [104]) & - & - & - & - & $\checkmark$ \\
\hline Perceived stress & Questionnaire (C) & Perceived Stress Scale (PSS [105]) & - & - & - & - & $\checkmark$ \\
\hline Childhood trauma & Questionnaire (C) & Childhood Trauma Questionnaire (CTQ [106]) & - & - & - & - & $\checkmark$ \\
\hline Victimisation & Interview (C) & $\begin{array}{l}\text { Juvenile Victimization Questionnaire 2nd revision (JVQ-R2 } \\
{[107] \text { )—sections on victimisation by peers and siblings, }} \\
\text { internet/mobile harassment, and discriminatory attacks }\end{array}$ & - & - & - & - & $\checkmark$ \\
\hline Self-harm & Questionnaire (C) & Item assessing self-harm in the past 12 months [108] & - & - & - & - & $\checkmark$ \\
\hline \multicolumn{8}{|l|}{ Socio-environmental indices } \\
\hline $\begin{array}{l}\text { Sociodemographic } \\
\text { variables }\end{array}$ & Questionnaire $(\mathrm{P}, \mathrm{C})$ & $\begin{array}{l}\text { Items assessing child's sex, date of birth, and (by caregiver- } \\
\text { report only) child's self-ascribed ethnicity, parents' dates } \\
\text { and places of birth, child and family history of mental health } \\
\text { problems, and whether child had ever lived outside London }\end{array}$ & $\boldsymbol{v}$ & - & - & - & - \\
\hline
\end{tabular}


Table 2 continued

\begin{tabular}{|c|c|c|c|c|c|c|c|}
\hline \multirow[t]{2}{*}{ Domain } & \multirow{2}{*}{$\begin{array}{l}\text { Assessment method } \\
\text { (informant) }\end{array}$} & \multirow{2}{*}{$\begin{array}{l}\text { Assessment } \\
\text { instrument }\end{array}$} & \multicolumn{5}{|c|}{ Assessment phase } \\
\hline & & & SCR & $\mathrm{BL}$ & FU1 & FU2 & $\mathrm{FU}^{\mathrm{a}}$ \\
\hline Ethnicity & Questionnaire (P) & $\begin{array}{l}\text { Office of Population Censuses and Surveys method of self- } \\
\text { ascription (2001 census) }\end{array}$ & - & $\checkmark$ & $\checkmark$ & $\boldsymbol{v}$ & - \\
\hline Migration history & Questionnaire (P) & Date of migration and country of origin & - & $\checkmark$ & $\checkmark$ & $\boldsymbol{v}$ & - \\
\hline $\begin{array}{l}\text { Home, school, and } \\
\text { community supports }\end{array}$ & Questionnaire (C) & Middle Development Index items [109] & - & $\boldsymbol{v}$ & $\checkmark$ & $\checkmark$ & - \\
\hline Sociodemographic context & Questionnaire (P) & $\begin{array}{l}\text { UK Medical Research Council Sociodemographic Schedule } \\
\text { on housing and living (migration) circumstances; religious } \\
\text { engagement }\end{array}$ & - & $\checkmark$ & $\boldsymbol{v}$ & $\boldsymbol{v}$ & - \\
\hline Socio-economic Status & Questionnaire (P) & $\begin{array}{l}\text { National Statistics Socio-Economic Classification (NS-SEC } \\
\text { [110]); household income; educational attainment }\end{array}$ & - & $\boldsymbol{v}$ & $\checkmark$ & $\checkmark$ & - \\
\hline Financial income & Questionnaire (C) & Items assessing income sources and total income per week & - & - & - & - & $\checkmark$ \\
\hline \multicolumn{8}{|l|}{ Biological indices } \\
\hline \multirow[t]{2}{*}{ DNA/mRNA } & Buccal sample (C) & Collected at the research session and in home environment & - & $\checkmark$ & $\checkmark$ & $\boldsymbol{V}$ & $\checkmark$ \\
\hline & Blood sample (C) & Collected at the research session & - & $\checkmark$ & $\checkmark$ & $\boldsymbol{v}$ & $\boldsymbol{V}$ \\
\hline Cortisol & $\begin{array}{l}\text { Saliva samples }(\mathrm{C}) \text {; } \\
\text { hair sample }(\mathrm{C})\end{array}$ & $\begin{array}{l}\text { Home collection of multiple saliva samples throughout the day } \\
\text { at FU2 [43]; hair sample collected in the research session at } \\
\text { FU3 }\end{array}$ & - & - & $\checkmark$ & - & $\checkmark$ \\
\hline Pubertal status & Questionnaire $(\mathrm{P}, \mathrm{C})$ & Pubertal Development Scale [111] & - & $\boldsymbol{V}$ & $\checkmark$ & $\boldsymbol{V}$ & - \\
\hline \multicolumn{8}{|l|}{ Neuromotor function } \\
\hline Laterality/handedness & Questionnaire (C) & $\begin{array}{l}\text { Annett Hand Preference Questionnaire [112], plus items from } \\
\text { the Edinburgh Handedness Inventory [113] and Coren's } \\
\text { Lateral Preference Scale [114] }\end{array}$ & - & $\checkmark$ & $\checkmark$ & $\boldsymbol{v}$ & - \\
\hline Gross and fine motor skills & Standardised test $(\mathrm{C})$ & Purdue Pegboard [115] & - & $\boldsymbol{v}$ & $\checkmark$ & $\boldsymbol{v}$ & - \\
\hline $\begin{array}{l}\text { Involuntary dyskinetic } \\
\text { movements }\end{array}$ & $\begin{array}{l}\text { Standardised rating } \\
\text { (C) }\end{array}$ & $\begin{array}{l}\text { Dyskinesia Identification System Condensed User Scale [116] } \\
\text { (coded from video recording) }\end{array}$ & - & $\checkmark$ & - & - & - \\
\hline \multicolumn{8}{|l|}{ Brain structure and function } \\
\hline General intelligence & Standardised test $(\mathrm{C})$ & Wechsler Abbreviated Scale of Intelligence (WASI [117]) & - & $\boldsymbol{V}$ & $\checkmark$ & $\boldsymbol{V}$ & $\boldsymbol{\sim}$ \\
\hline Scholastic achievement & Standardised test $(\mathrm{C})$ & $\begin{array}{l}\text { Wechsler Individual Achievement Test } 2 \text { nd UK edition } \\
\text { (WIAT [118]): word reading, numerical operations, and } \\
\text { spelling subtests }\end{array}$ & - & $\boldsymbol{V}$ & $\checkmark$ & $\boldsymbol{V}$ & - \\
\hline Processing speed & Standardised test $(\mathrm{C})$ & Symbol Digit Modality Test [119] & - & - & - & $\boldsymbol{v}$ & - \\
\hline Memory & Standardised test $(\mathrm{C})$ & $\begin{array}{l}\text { Wide Range Assessment of Memory and Learning 2nd edition } \\
\text { (WRAML2 [120]): verbal learning and memory, visual } \\
\text { learning and memory, verbal delayed recall, recognition } \\
\text { (verbal and nonverbal), and working memory subtests }\end{array}$ & - & $\checkmark$ & $\checkmark$ & $\boldsymbol{v}$ & - \\
\hline Executive function & Standardised test $(\mathrm{C})$ & $\begin{array}{l}\text { Delis-Kaplan Executive Function System (D-KEFS [121]): } \\
\text { verbal fluency, colour-word interference (Stroop), and tower } \\
\text { test subtests }\end{array}$ & - & $\checkmark$ & $\checkmark$ & $\boldsymbol{v}$ & - \\
\hline $\begin{array}{l}\text { Facial emotion } \\
\text { recognition }\end{array}$ & Computer task $(\mathrm{C})$ & Penn Emotion Discrimination Task (EmoDiff40) [122] & - & $\boldsymbol{V}$ & $\checkmark$ & $\boldsymbol{V}$ & - \\
\hline $\begin{array}{l}\text { Facial emotion } \\
\text { discrimination }\end{array}$ & Computer task (C) & Emotion Recognition Test-40 Faces version (ER-40) [123] & - & $\checkmark$ & $\checkmark$ & $\boldsymbol{v}$ & - \\
\hline Brain structure & $\begin{array}{l}\text { Magnetic Resonance } \\
\text { Imaging }(C)\end{array}$ & $\begin{array}{l}\text { Spoiled Gradient Recalled acquisition (Magnetization } \\
\text { Prepared Rapid Acquisition Gradient Echo-additional scan } \\
\text { completed in a subset only) }\end{array}$ & - & $\checkmark$ & $\checkmark$ & $\boldsymbol{V}$ & - \\
\hline Mismatch negativity & Computer task (C) & $\begin{array}{l}\text { Duration deviant passive auditory oddball task: ERP } \\
\text { recordings [55] }\end{array}$ & - & $\boldsymbol{V}$ & $\checkmark$ & $\boldsymbol{v}$ & - \\
\hline Working memory & Computer task $(\mathrm{C})$ & Spatial N-Back task: functional MRI (variant of [124]) & - & $\boldsymbol{V}$ & $\checkmark$ & $\boldsymbol{V}$ & - \\
\hline Attention & Computer task $(\mathrm{C})$ & $\begin{array}{l}\text { Auditory novelty oddball task: ERP recordings and functional } \\
\text { MRI (variant of [125]) }\end{array}$ & - & $\boldsymbol{v}$ & $\checkmark$ & $\boldsymbol{V}$ & - \\
\hline Error-related processing & Computer task $(\mathrm{C})$ & Go/No-Go task: ERP recordings and functional MRI [53] & - & $\checkmark$ & $\checkmark$ & $\checkmark$ & - \\
\hline Response inhibition & Computer task $(\mathrm{C})$ & $\begin{array}{l}\text { Stop task: ERP recordings and functional MRI (variant of } \\
\text { [126]) }\end{array}$ & - & $\checkmark$ & $\checkmark$ & $\boldsymbol{v}$ & - \\
\hline \multicolumn{8}{|c|}{ Service use, support, and quality of life } \\
\hline Service utilisation & Questionnaire $(\mathrm{P}, \mathrm{C})$ & Services Assessment for Children and Adolescents [127] & - & - & $\boldsymbol{\sigma}^{+}$ & - & $\boldsymbol{v}^{+}$ \\
\hline
\end{tabular}


Table 2 continued

\begin{tabular}{|c|c|c|c|c|c|c|c|}
\hline \multirow[t]{2}{*}{ Domain } & \multirow{2}{*}{$\begin{array}{l}\text { Assessment method } \\
\text { (informant) }\end{array}$} & \multirow{2}{*}{$\begin{array}{l}\text { Assessment } \\
\text { instrument }\end{array}$} & \multicolumn{5}{|c|}{ Assessment phase } \\
\hline & & & SCR & $\mathrm{BL}$ & FU1 & FU2 & $\mathrm{FU}^{\mathrm{a}}$ \\
\hline Resource access & Questionnaire $(\mathrm{P}, \mathrm{C})$ & Resource Generator-UK, expert advice subscale [128] & - & - & $\boldsymbol{\nu}^{+}$ & - & $\boldsymbol{⿰}^{+}$ \\
\hline Social cohesion & Questionnaire $(\mathrm{P}, \mathrm{C})$ & Items assessing neighbourhood social cohesion [129] & - & - & $\boldsymbol{\nu}^{+}$ & - & $\boldsymbol{\nu}^{+}$ \\
\hline Peer interaction & Questionnaire (C) & $\begin{array}{l}\text { Child Health and Illness Profile [130] peer interaction and } \\
\text { satisfaction scale }\end{array}$ & - & - & - & - & $\boldsymbol{\nu}^{+}$ \\
\hline Mental health literacy & Questionnaire (C) & $\begin{array}{l}\text { Self-report questionnaires on two vignettes depicting persons } \\
\text { with (1) depression and (2) psychosis. Assesses recognition } \\
\text { of the disorder, intended help-seeking, beliefs about } \\
\text { interventions and prevention, stigmatising attitudes, and } \\
\text { exposure to mental disorders [131] }\end{array}$ & - & - & - & - & $\boldsymbol{\sim}^{+}$ \\
\hline $\begin{array}{l}\text { Self-identification as } \\
\text { having a mental illness }\end{array}$ & Questionnaire (C) & $\begin{array}{l}\text { Self-Identification as Having a Mental Illness Scale (SELF-I) } \\
\text { assessing perceived need for professional help and appraisal } \\
\text { of problem as mental illness [132] adapted for young people }\end{array}$ & - & - & - & - & $\boldsymbol{\sim}^{+}$ \\
\hline \multicolumn{8}{|l|}{ Stigma } \\
\hline Public stigma & Questionnaire $(\mathrm{P}, \mathrm{C})$ & Reported and Intended Behaviour Scale [133] & - & - & $\boldsymbol{\alpha}^{+}$ & - & $\boldsymbol{\nu}^{+}$ \\
\hline Stigma coping & Questionnaire (C) & $\begin{array}{l}\text { Items assessing cognitive appraisal of mental health stigma } \\
\text { [134] }\end{array}$ & - & - & - & - & $\boldsymbol{\nu}^{+}$ \\
\hline
\end{tabular}

Assessment phase-SCR screening assessment (age 9-11 years; data collected during 2005-2010 in 7966 children screened with questionnaires at primary school), BL baseline assessment (age 9-12 years), FU1 follow-up assessment 1 at approximately 24-months post-baseline (age 11-14 years), FU2 follow-up assessment 2 at approximately 48-months post-baseline (age 13-16 years), FU3 follow-up assessment 3 at approximately 72 -months post-baseline (age 17-18 years; ${ }^{\text {a }}$ self-report information only collected)

$P$ primary caregiver, $C$ child, $T$ teacher

+ Indicates measures collected in the longitudinal community cohort in addition to the longitudinal selected cohort

Fig. 1 Venn diagram indicating the percentages of children displaying antecedents within each domain of the triad (overlapping segments indicate children who displayed multiple antecedents); based on data from 1504 child-caregiver dyads who completed screening questionnaires

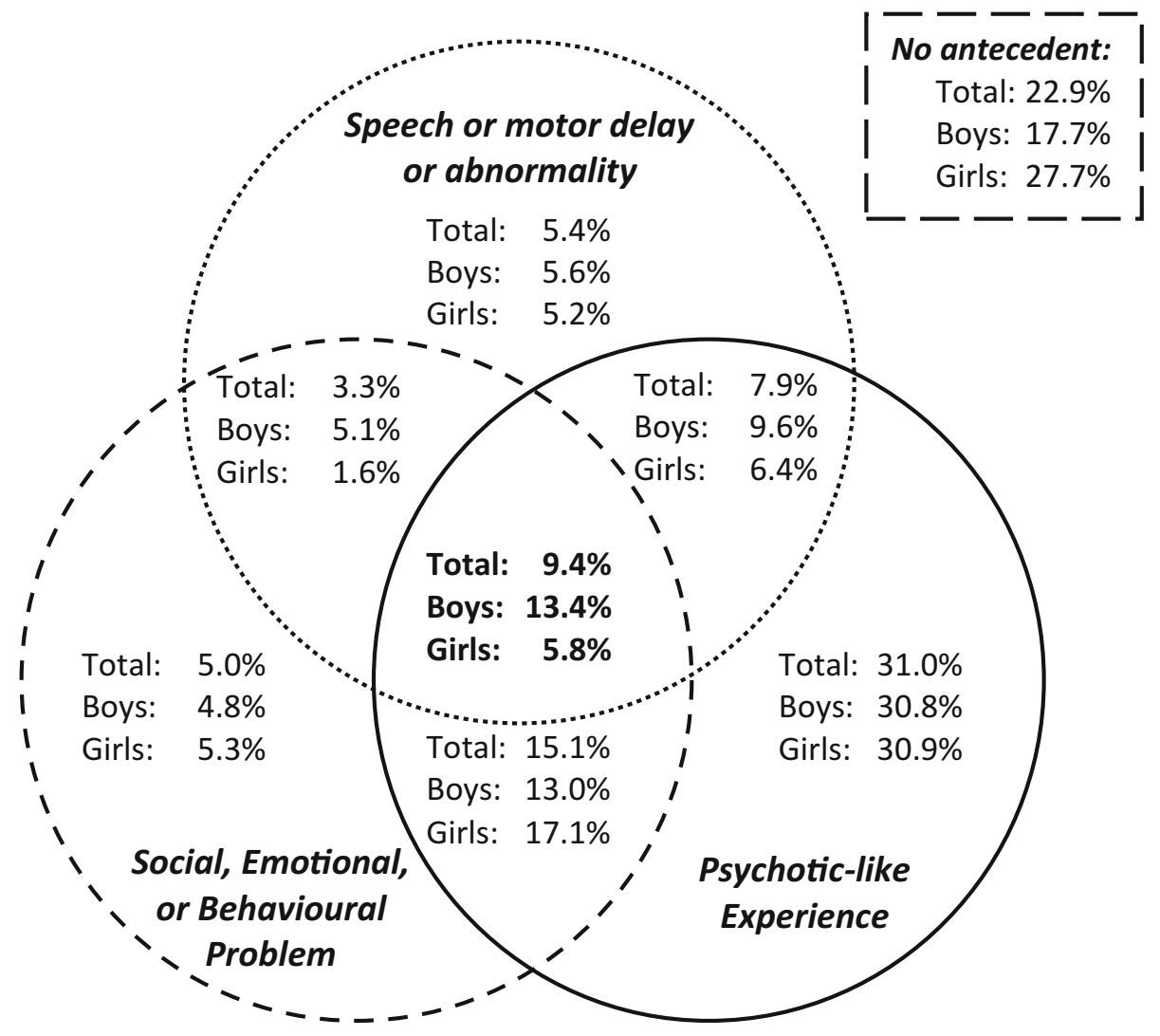


schizophrenia on the screening questionnaires were similarly elevated (3.4\% of children). The antecedent triad was significantly more prevalent in males relative to females (Fig. 1), and more common among children of AfricanCaribbean [9, 17] and black African [9] ethnicity relative to white British children, mimicking the increased incidence of schizophrenia $[18,19]$ in these ethnic minority groups in the UK. Conversely, children of south Asian ethnicity were less likely relative to the white British population to present the antecedent triad [9], providing a potential opportunity to identify protective, as well as risk, processes that might be operating prior to illness onset in schizophrenia.

\section{Childhood PLEs}

An early contribution from the CHADS programme was the development of a nine-item self-report questionnaire assessing a range of delusion- and hallucination-like experiences for use by children aged 9-11 years [7], comprising an adaption and extension of items from the Diagnostic Interview Schedule for Children [20]. Almost two-thirds of children reported at least one PLE, implying that these experiences may be part of a spectrum of normative childhood experience in middle childhood [15]. Recent metaanalyses indicate that auditory hallucinations are more prevalent among children aged 9-12 years (median prevalence: $17 \%$ [21]) than in the adolescent $(7.5 \%)$ or adult (5-8\% [22]) general population, with questionnaire measures typically eliciting higher rates than clinical interviews [23]. Discrepancy in our rates of self- and caregiver-reported childhood PLEs (66.0 vs. $9.7 \%$; also reported by others [24, 25]) implies that children do not necessarily report these phenomena to adults, or that they interpret their experiences differently than do caregivers. Whilst the majority of children reporting PLEs will not go on to develop a SSD in adulthood, for many children, these experiences are not benign; more than a third (40.9\%) reported distress or functional impairment associated with these experiences, particularly those presenting the antecedent triad (68.1\% [9]). In children, similarly to the adult population [26], the PLE items load on a construct which is correlated with, but dissociable from, the constructs underpinning internalising and externalising problems [15]. Two items assessing hallucination-like experiences appeared most suited to identifying children with vulnerability to psychotic illness in the general population [15], with such items previously also showing strong criterion validity for psychotic symptoms elicited by diagnostic interview among 11-13-year olds [24].

\section{Persistence of PLEs}

Meta-analytic data approximate that $75-90 \%$ of developmental psychotic experiences are transitory and relatively benign, but that these experiences may persist to become clinically relevant, depending on the degree of environmental risk to which the person is additionally exposed [22]. Our longitudinal data indicated that two in five children $(39 \%)$ who reported PLEs at baseline continued to report these experiences approximately 2 years later, in adolescence [27]. Persistent PLEs from childhood (9-11 years) were associated with internalising and externalising psychopathology in adolescence [27], implying that interventions targeting persistent PLEs might not only alleviate risk for later schizophrenia, but more immediately, reduce common adolescent psychopathology.

\section{Trajectories of psychopathology}

Though PLEs and internalising and externalising psychopathology in middle childhood all constitute replicated antecedents of schizophrenia, our data indicate that internalising and externalising psychopathology experienced only during childhood is not associated with increased risk for PLEs in adolescence, whereas psychopathology that persists from childhood into adolescence or is incident in adolescence confers increased risk for later PLEs [28]. This work suggests a need for further investigation into timely targeted interventions designed to prevent progression from early symptom development to full disorder.

\section{Psychological, cognitive, and neurobiological findings}

Detailed, laboratory-based assessments have been conducted biennially in the selected sample to determine the extent to which hallmark disturbances of schizophrenia are present already during the early (pre-prodromal) at-risk phase of illness; findings to date are summarised in Table 3.

\section{Psychopathology and stress responsivity}

Prospective longitudinal studies of both general population [10] and familial high-risk [29] cohorts indicate psychopathology during childhood and adolescence in individuals who later develop SSD. We investigated social withdrawal in children with different vulnerability profiles for the disorder, namely, children at putatively elevated symptomatic risk of schizophrenia (ASz) and those at elevated genetic risk due to a family history of illness (FHx). Both ASz and FHx children aged 9-14 years presented significantly elevated levels of parent-reported social withdrawal relative to their TD peers, though the magnitude of the effect was greater among ASz children [30]; thus, social withdrawal may be a more prominent feature among children at elevated symptomatic risk. 
Table 3 Summary of psychopathological, cognitive, neurobiological, and HPA axis abnormalities observed among children presenting antecedents of schizophrenia (ASz) and a family history of illness
(FHx) compared with the pattern of abnormalities typically observed among adults with established psychosis

\begin{tabular}{|c|c|c|c|}
\hline Marker & Adult psychosis vs. HC & ASz vs. TD children & FHx vs. TD children \\
\hline \multicolumn{4}{|l|}{ Psychopathology and stress responsivity } \\
\hline Social withdrawal $^{\text {b }}$ & $\uparrow$ & $\uparrow$ & $\uparrow$ \\
\hline Psychosocial stress exposure $^{\mathrm{d}}$ & $\uparrow$ & $\uparrow$ & $\uparrow$ \\
\hline Psychosocial stress reactivity ${ }^{\mathrm{d}}$ & $\uparrow$ & $\uparrow$ & $\uparrow$ \\
\hline \multicolumn{4}{|l|}{ Cognitive impairments ${ }^{\mathrm{c}}$} \\
\hline General intelligence (IQ) & $\downarrow$ & $\downarrow$ & $\downarrow$ \\
\hline Scholastic achievement & $\downarrow$ & $\downarrow$ & $\downarrow$ \\
\hline Verbal memory & $\downarrow$ & $\downarrow$ & $\downarrow$ \\
\hline Visual memory & $\downarrow$ & - & - \\
\hline Working memory (verbal) & $\downarrow$ & $\downarrow$ & $\downarrow$ \\
\hline Executive function (verbal fluency) & $\downarrow$ & $\downarrow$ & $\downarrow$ \\
\hline Executive function (inhibition) & $\downarrow$ & $\downarrow$ & $\downarrow$ \\
\hline Facial emotional processing ability & $\downarrow$ & $\downarrow$ & Not examined \\
\hline \multicolumn{4}{|l|}{ Neurobiological abnormalities } \\
\hline Grey matter volume (left STG/MTG and right MTG) ${ }^{\mathrm{a}}$ & $\downarrow$ & $\uparrow \downarrow$ & Not examined \\
\hline White matter volume (left SLF, ILF, and OR) ${ }^{\mathrm{a}}$ & $\downarrow$ & $\uparrow$ & Not examined \\
\hline Error-related negativity ERP component amplitude ${ }^{\mathrm{a}}$ & $\downarrow$ & $\downarrow$ & Not examined \\
\hline Mismatch negativity ERP component amplitude ${ }^{\mathrm{a}}$ & $\downarrow$ & $\uparrow$ & Not examined \\
\hline Dyskinetic movement abnormalities $^{\mathrm{a}}$ & $\uparrow$ & $\uparrow$ & Not examined \\
\hline \multicolumn{4}{|l|}{ HPA axis dysfunction } \\
\hline Diurnal cortisol $^{\mathrm{d}}$ & $\uparrow$ & - & - \\
\hline Cortisol awakening response $^{\mathrm{d}}$ & $\downarrow$ & - & $\downarrow$ \\
\hline Pituitary volume $^{\mathrm{d}}$ & $\uparrow \downarrow$ & - & - \\
\hline
\end{tabular}

$H C$ healthy control, TD typically developing children, $\downarrow$ decreased in psychosis/high-risk group relative to HC/TD group; $\uparrow$ Increased in psychosis/high-risk group relative to HC/TD group, - no difference between psychosis/high-risk group and HC/TD group, STG superior temporal gyrus, $M T G$ medial temporal gyrus, $S L F$ superior longitudinal fasciculus, $I L F$ inferior longitudinal fasciculus, $O R$ optic radiation, $E R P$ eventrelated potential, $H P A$ hypothalamic-pituitary-adrenal

Encompassing CHADS assessments completed at age ${ }^{\mathrm{a}}$ 9-12 years, ${ }^{\mathrm{b}}$ 9-14 years, ${ }^{\mathrm{c}}$ 9-16 years, and ${ }^{\mathrm{d}} 11-14$ years

With respect to their response to psychosocial stressors (e.g. major life events, childhood trauma, and milder daily hassles), which have been shown to contribute to the development and maintenance of psychosis in retrospective and prospective studies [31-33], FHx and ASz children aged 11-14 years reported greater exposure to negative life events and daily hassles, respectively, compared to TD children, and were more distressed by these experiences [34]. Thus, while both groups were more responsive to psychosocial stressors, $\mathrm{ASz}$ and FHx children may be susceptible to different stressors. Relative to TD children [35], both risk groups experienced higher rates of physical punishment (thought to be on a continuum with childhood maltreatment, a replicated risk factor for SSD [36]).

\section{Cognitive impairment}

In light of meta-analytic data indicating premorbid IQ impairment in children who later develop schizophrenia
[37], with low IQ increasing the risk of later schizophrenia in a dose-response fashion [38], we investigated trajectories of neurocognitive function in children with different vulnerability profiles. In initial cross-sectional analyses conducted in $\mathrm{ASz}$ and TD groups only, we observed impairments in general intelligence, verbal memory, working memory, and executive function among $\mathrm{ASz}$ children aged 9-12 years [39] which were less pervasive and smaller in magnitude than those characterising adults with schizophrenia [40], but similar to those observed among CHR individuals [41, 42]. In subsequent analyses performed on a larger, partially overlapping sample, ASz children performed at a level intermediate to FHx children with high familial loading ( $\geq 1$ first-degree or $\geq 2$ seconddegree relatives) and FHx children with low familial loading (one affected second-degree relative only) across a range of neurocognitive subtests [43]. Preliminary analysis of longitudinal data collected across three biennial assessments spanning 9-16 years indicates different patterns of 
cognitive development through adolescence in $\mathrm{ASz}$ and FHx children relative to TD children. ASz and FHx children exhibited stable deficits in IQ, scholastic achievement, verbal working memory, and specific domains of executive function, but greater gains in verbal memory relative to their TD peers [44], with relatively more subtle differences apparent between the high risk groups (as has been indicated also in meta-analysis of older samples of CHR youth relative to youth with family history [45]). Our findings highlight the uneven pace of development of different cognitive abilities throughout adolescence in at-risk youth, which might reflect divergence in the rate of maturation in some brain areas among at-risk youth compared to their TD peers.

The cognitive impairments characterising ASz children also extend to social cognition. Consistent with the impaired ability of individuals with schizophrenia [46] and CHR youth [47] to recognise facial emotions, ASz children (9-15 years) showed moderate deficits in facial emotion recognition, particularly sad and angry expressions [48]. Future analyses will examine whether these facial emotion processing deficits also characterise FHx children; previous investigations of older youth (13-25 years) indicate that such impairments are more prominent among CHR individuals than those with family history of schizophrenia [49].

\section{Neurobiological abnormalities}

Antipsychotic medication and neurodegenerative processes associated with disease progression potentially confound neurobiological studies of adults with established schizophrenia, and only the latter are overcome in studies of CHR youth (a substantial proportion of whom also receive psychotropic treatment [50]). Our work examining medication-naive at-risk children thus offers important insights into the aetiology of neurobiological abnormalities underlying schizophrenia.

We have shown that a subset of the structural brain abnormalities associated with schizophrenia (typically, widespread volume decreases, but also increases, encompassing the frontal and temporal lobes, medial temporal regions, anterior cingulate, insula, and thalamus [51]) precede the prodromal phase of illness. By age 9-12 years, $\mathrm{ASz}$ children present significant grey matter volume reduction in the right middle temporal gyrus, but significant volume increase in the left superior and middle temporal gyri relative to TD children [52]. ASz children also show increased white matter volume in the left inferior parietal lobe, occipital lobe, and superior temporal gyrus, corresponding to parts of the superior longitudinal fasciculus, inferior longitudinal fasciculus, and optic radiation. Whilst these abnormalities contrast with temporal lobe volume reductions typically reported in schizophrenia, our findings imply that changes in this region may be among the first structural brain abnormalities to emerge. Our longitudinal data will allow us to track further structural changes through adolescence to illness onset.

Abnormalities of brain function that characterise adults with schizophrenia, as indexed by event-related potentials (ERP), are present also in ASz children. We have investigated two well-defined ERP components at 9-12 years: error-related negativity (ERN), a brain potential elicited following detection of an error, and auditory mismatch negativity (MMN), an ERP component that reflects an automatic attentive process detecting discrepancy between an incoming sound and the memory trace of preceding sounds. Similar to patients with schizophrenia, ASz children showed reduced amplitude of the ERN component [53]. It is proposed that the ERN is generated to an error following a dopamine-mediated negative reinforcement learning signal sent from the basal ganglia to the anterior cingulate cortex [54]; thus, reduced ERN in schizophrenia (and $\mathrm{ASz}$ children) might reflect disruption of these dopamine pathways. In contrast with the decreased MMN amplitude typically observed in schizophrenia, however, $\mathrm{ASz}$ children were characterised by increased MMN amplitude relative to TD children [55], indicating the need for longitudinal data to establish the developmental trajectory of this component in at-risk children.

We have further demonstrated that involuntary dyskinetic movements, thought to index the abnormal striatal dopamine levels that characterise individuals with schizophrenia, are more frequent among ASz children aged 9-12 years compared to TD children [56]. These abnormalities (rated blindly using videotapes) were observed in the facial regions (e.g. tics, grimacing) and upper body (e.g. shoulder/hip torsion, finger or wrist extensions) and are similar to those reported among children who later develop schizophrenia [57, 58] and adolescents with schizotypal personality disorder [59].

\section{Hypothalamic-pituitary-adrenal (HPA) axis dysfunction}

Our study of medication-naïve, non-help-seeking children has also allowed us to investigate whether abnormalities within the HPA axis (the primary system involved in coordinating the physiological response to stress), which have been observed among first-episode psychosis patients and CHR youth [60-63], also characterise earlier stages of illness. It is hypothesised that, among individuals at increased vulnerability for psychosis, HPA axis hyperactivity (triggered by psychosocial stress) elicits elevated cortisol levels, which in turn contribute to the clinical features of psychosis by augmenting dopamine activity [64, 65]. However, HPA abnormalities reported among first- 
episode and CHR patients [including elevated daytime cortisol levels, a blunted cortisol awakening response (CAR), and pituitary volume enlargements] might simply be a consequence of the stress associated with emerging illness.

By age 11-14 years, FHx children (but not ASz children) showed a blunted CAR [43] that was not explained by experiences of psychosocial stressors and was more prominent among FHx children with a first-degree relative with schizophrenia than among FHx with an affected second-degree relative. In contrast to hypotheses, neither $\mathrm{ASz}$ nor FHx children were characterised by higher diurnal cortisol levels. Nonetheless, among both $\mathrm{FHx}$ and $\mathrm{ASz}$ children, abnormal cortisol levels (i.e. higher diurnal cortisol levels and greater blunting of the CAR) were associated with poorer memory and executive function, possibly reflecting underlying dysfunction in the brain regions which mediate both HPA axis function and these cognitive functions [43]. Neither ASz nor FHx children were characterised by pituitary volume enlargements [35], which contrasts with those identified among individuals with firstepisode psychosis [66-69] and in some (but not all) studies of older individuals at-risk for psychosis [69, 70]. Among FHx children only, pituitary volume was negatively associated with current distress relating to negative life events and exposure to physical punishment [35], implying that psychosocial stressors may contribute to pituitary volume changes among those with family history. Overall, our findings tentatively suggest that the blunted CAR might be an early (possibly genetically mediated) marker of psychosis vulnerability, while HPA axis hyperactivity (as indexed by elevated daytime cortisol levels and enlarged pituitary volume) might emerge closer to disease onset.

\section{Intervention findings}

Many children and adolescents experiencing mental health difficulties do not receive appropriate professional care [71, 72]. Data from the CHADS longitudinal community cohort have highlighted the central role of caregivers' attitudes and experiences on young people's service use (in health and education settings), particularly the influence of caregivers' perceptions of stigma and their own service use history [73]. Targeting stigma among caregivers may be a key strategy in bridging the gap between young people's need and service use.

We have developed a cognitive behavioural intervention for children aged 9-14 years who experience PLEs and emotional problems which is designed to reduce emotional symptoms, improve coping and resilience, and help children manage distressing PLEs [74]. In a pilot with four children, child and therapist satisfaction with the programme was high, and emotional problems and PLE frequency and impact all decreased during intervention. A randomised controlled evaluation of the intervention with clinically referred samples of children is underway (Table 1, "4. CHADS-associated intervention samples"). Distressing PLEs are common in these children. In pretreatment data, negative life events, emotional symptoms, cognitive biases (e.g. probabilistic reasoning and jumping to conclusions biases), and negative schematic beliefs about self and others independently contributed to PLE severity [75, 76]. Further, negative schematic beliefs mediated the relationship between experiences of bullying and PLEs [77]. These psychosocial and cognitive processes show different associations with PLE content (e.g. paranoia, hallucinations) and dimensional attributes (e.g. frequency, impact) [78] and provide potential targets for psychological intervention in children with PLEs.

\section{Discussion}

The CHADS programme, encompassing complementary community and selected cohorts, has yielded findings that may aid efforts to delineate the aetiological processes underlying SSD, and inform strategies to identify and treat at-risk individuals earlier than is currently feasible. Building on the work of early prospective longitudinal studies of both general population and familial high-risk cohorts (which were typically restricted to examination of psychopathological features), we have identified several neurobiological markers that may index early, premorbid pathophysiology on a developmental trajectory to SSD. By means of our large, unselected sample (from an ethnically diverse, urban population), we have contributed epidemiological findings demonstrating that the prevalence of the triad of schizophrenia antecedents is elevated among males and specific ethnic groups, and that PLEs in particular can be distressing and persistent for some children, depending on co-occurrence of internalising and externalising symptoms or other antecedents of schizophrenia. Furthermore, in a clinically referred sample of children, we have shown that levels of distress and severity associated with PLEs are related to psychological and cognitive constructs that may be amenable to cognitive-behavioural interventions.

\section{Scientific and theoretical advancements}

\section{Aetiological theories}

Our findings align with the recent sociodevelopmentalcognitive model of schizophrenia [79] that integrates dopaminergic, neurodevelopmental, sociodevelopmental, and cognitive theories. Whilst it has long been suspected that schizophrenia is preceded by abnormal 
neurodevelopment commencing in early life, prospective studies utilising magnetic resonance imaging and ERP technology have been lacking. Our work has provided preliminary evidence that several structural [52] and functional brain abnormalities [53, 55] associated with schizophrenia are evident in at-risk children by age 9-12 years. Moreover, increased dyskinetic movements [56] and reduced amplitude of the ERN brain potential [53] in ASz children hint at early abnormalities in dopamine regulation. In line with the cognitive component of the model, our work in clinically referred children has indicated a number of cognitive biases associated with PLEs $[75,76]$. We have identified a number of potential social adversities which might contribute to such biases (e.g. physical punishment [35], negative life events, and daily hassles [34]) that are more prevalent and elicit greater distress in at-risk children than typically developing children. Whilst we have found no evidence as yet that these stressful experiences elicit HPA axis abnormalities in ASz and FHx children [35, 43], developmental changes may render the HPA axis more susceptible to environmental stressors. Thus, many of the components within the sociodevelopmental-cognitive model of schizophrenia [79] that are hypothesised to contribute to the development of schizophrenia are detectable in at-risk children, but further work is required to integrate these findings for testing.

\section{Genetically and symptomatically driven risk markers}

The CHADS findings augment those of previous longitudinal studies, commencing in the 1950 s, which prospectively followed offspring of parents with schizophrenia [29]. We offer evidence confirming neurocognitive impairments and social withdrawal in young relatives of individuals with schizophrenia [80-82], and new findings regarding experiences of psychosocial stress and HPA axis function in FHx children (which, until now, have been studied only in adult relatives who may no longer be 'at-risk' for the disorder). By characterising development of both ASz and FHx children, we may identify risk markers that are primarily genetically mediated (and may be shared by non-symptomatic relatives), and others present only in individuals displaying the antecedent phenotype [83]. The latter offers the prospect of identifying candidate mechanisms associated with emerging illness. Future investigations might benefit from incorporating at-risk groups identified by alternative means (e.g. youth with a family history of bipolar disorder or those with 22q11.2 deletion syndrome).

\section{Timing and trajectories}

To date, we have investigated only a subset of the potential markers that may be affected in at-risk children, and while many of these markers have shown abnormalities that are similar to those observed in adults with schizophrenia and CHR youth, there are notable exceptions. For example, ASz children were characterised by increased amplitude of the MMN potential [55], and relative increases in grey and white matter in the temporal lobes [52]; it is possible that these patterns may reverse as the brain undergoes maturation in adolescence. Our investigations revealed no evidence of anticipated abnormalities such as elevated diurnal cortisol [43] or pituitary volume enlargement [35] among either $\mathrm{ASz}$ or $\mathrm{FHx}$ children, implying that HPA axis hyperactivity may emerge more proximally to illness onset. Having identified potential premorbid markers of illness (albeit these must be shown to be robust with replication in other samples), an important next step will be to determine whether these markers vary with symptom fluctuation and are responsive to intervention. Studies that assess changes in both biological and psychological markers in response to intervention are needed.

\section{Implications}

The psychosocial, cognitive, and neurobiological features that we have found to characterise $\mathrm{ASz}$ and $\mathrm{FHx}$ children might potentially be used to enhance the accuracy with which individuals at-risk of SSD can be identified in the general population and/or via relatives with SSD. We anticipate that, instead of SSD, some putatively at-risk children will develop other psychiatric disorders, whilst others will develop no disorder. Longitudinal follow-up of the cohort is needed to determine the specificity and sensitivity with which the antecedent triad and associated psychopathological markers distinguish between these outcomes. From a clinical perspective, our findings have already informed the development of a new psychological intervention for children aged 8-14 years which targets current difficulties experienced by the children (e.g. distressing PLEs and emotional symptoms [74]). We hope that such intervention might also avert more serious mental health problems in the future.

Research into the early identification and prevention of SSD has focussed predominantly on youth in late adolescence or early adulthood who present features consistent with the prodromal phase of illness immediately preceding psychosis onset, with little consideration given to vulnerable children or younger adolescents in an earlier phase of illness. Our research demonstrates that this group, who may present different clinical and biological features and treatment needs to those meeting CHR criteria [84], should not be overlooked. Indeed, children presenting multiple antecedents of schizophrenia present a range of social, psychological, cognitive, and biological abnormalities characteristic of adults with schizophrenia, though they are 
(at present) less marked and diffuse, thereby providing a potential window for early intervention. Our new method of screening community samples to identify children displaying multiple antecedents of schizophrenia (who are putatively in the premorbid illness phase) offers a tool to facilitate research, and might, with refinements informed by ongoing research, complement established methods for identifying $\mathrm{CHR}$ youth in the later, prodromal phase of illness. Further research across the CHADS cohorts is underway to: (1) characterise developmental changes through adolescence and into young adulthood that might constitute viable targets for early preventative interventions, (2) identify neurobiological, neurocognitive, and psychopathological changes that might signal imminent risk of transition to psychosis, and (3) develop novel, innovative interventions that might alter the course of illness in vulnerable individuals. Through these research endeavours, we hope ultimately to improve outcomes for individuals who may be on the trajectory to this devastating disorder.

Acknowledgments The authors thank the participants in the study and the research staff and students who contributed to data collection. We thank Professors Sheilagh Hodgins, Robin Murray, Eric Taylor, and Doctors Helen Fisher and Sara Evans-Lacko for their contributions to the design of particular assessment phases within the London Child Health and Development Study, and gratefully acknowledge contributions to the study from many other research and clinical academics. We also thank Professor Philip McGuire for his helpful discussion of this review. The London Child Health and Development Study has been supported by funding from a National Institute for Health Research (NIHR) Postdoctoral Fellowship (PAS/01/05/PDA/ 042) and Career Development Fellowship (CDF/08/01/015); a National Alliance for Research on Schizophrenia and Depression (NARSAD) Young Investigator Award (2005); Bial Foundation Research Grants (35/06 and 194/12); the British Medical Association Margaret Temple Award for schizophrenia research (2006 and 2012); a Psychiatry Research Trust grant (2010), and a Waterloo Foundation Child Development Fund grant (164/1719). KRL is supported by funding from the Schizophrenia Research Institute, utilising infrastructure funding from the New South Wales Ministry of Health.

\section{Compliance with ethical standards}

Conflict of interest The authors declare that they have no conflict of interest.

Ethical standards All assessment phases of the London Child Health and Development Study received approval from the appropriate UK ethics committee, and have been performed in accordance with ethical standards that incorporate the 1964 Declaration of Helsinki and its later amendments. Participants provided written informed consent for participation at each research assessment.

Open Access This article is distributed under the terms of the Creative Commons Attribution 4.0 International License (http://crea tivecommons.org/licenses/by/4.0/), which permits unrestricted use, distribution, and reproduction in any medium, provided you give appropriate credit to the original author(s) and the source, provide a link to the Creative Commons license, and indicate if changes were made.

\section{References}

1. Fusar-Poli P, Borgwardt S, Bechdolf A, Addington J, RiecherRossler A, Schultze-Lutter F, Keshavan M, Wood S, Ruhrmann S, Seidman LJ, Valmaggia L, Cannon T, Velthorst E, De Haan L, Cornblatt B, Bonoldi I, Birchwood M, McGlashan T, Carpenter W, McGorry P, Klosterkotter J, McGuire P, Yung A (2013) The psychosis high-risk state: a comprehensive state-ofthe-art review. JAMA Psychiatry 70(1):107-120. doi:10.1001/ jamapsychiatry.2013.269

2. Fusar-Poli P, Bonoldi I, Yung AR, Borgwardt S, Kempton MJ, Valmaggia L, Barale F, Caverzasi E, McGuire P (2012) Predicting psychosis: meta-analysis of transition outcomes in individuals at high clinical risk. Arch Gen Psychiatry 69(3):220-229. doi:10.1001/archgenpsychiatry.2011.1472

3. Simon AE, Borgwardt S, Riecher-Rossler A, Velthorst E, de Haan L, Fusar-Poli P (2013) Moving beyond transition outcomes: meta-analysis of remission rates in individuals at high clinical risk for psychosis. Psychiatry Res 209(3):266-272. doi:10.1016/j.psychres.2013.03.004

4. Yung AR, Stanford C, Cosgrave E, Killackey E, Phillips L, Nelson B, McGorry PD (2006) Testing the ultra high risk (prodromal) criteria for the prediction of psychosis in a clinical sample of young people. Schizophr Res 84(1):57-66. doi:10. 1016/j.schres.2006.03.014

5. Klosterkotter J, Ebel H, Schultze-Lutter F, Steinmeyer EM (1996) Diagnostic validity of basic symptoms. Eur Arch Psychiatry Clin Neurosci 246(3):147-154

6. Tandon R, Keshavan MS, Nasrallah HA (2008) Schizophrenia, "just the facts" what we know in 2008. 2. Epidemiology and etiology. Schizophr Res 102(1-3):1-18. doi:10.1016/j.schres. 2008.04.011

7. Laurens KR, Hodgins S, Maughan B, Murray RM, Rutter ML, Taylor EA (2007) Community screening for psychotic-like experiences and other putative antecedents of schizophrenia in children aged 9-12 years. Schizophr Res 90(1-3):130-146. doi:10.1016/j.schres.2006.11.006

8. Laurens KR, Luo L, Matheson SL, Carr VJ, Raudino A, Harris F, Green MJ (2015) Common or distinct pathways to psychosis? A systematic review of evidence for developmental risk factors and antecedents of the schizophrenia spectrum disorders and affective psychoses. BMC Psychiatry 15:205. doi:10.1186/ s12888-015-0562-2

9. Matheson SL, Shepherd AM, Laurens KR, Carr VJ (2011) A systematic meta-review grading the evidence for non-genetic risk factors and putative antecedents of schizophrenia. Schizophr Res 133(1-3):133-142. doi:10.1016/j.schres.2011.09.020

10. Welham J, Isohanni M, Jones P, McGrath J (2009) The antecedents of schizophrenia: a review of birth cohort studies. Schizophr Bull 35(3):603-623. doi:10.1093/schbul/sbn084

11. Goodman R (1997) The strengths and difficulties questionnaire: a research note. J Child Psychol Psychiatry 38(5):581-586

12. Goodman R, Meltzer H, Bailey V (2003) The strengths and difficulties questionnaire: a pilot study on the validity of the selfreport version. Int Rev Psychiatry 15(1-2):173-177. doi:10. 1080/0954026021000046137

13. Department for Communities and Local Government (UK Government) (2011) The English Indices of Deprivation 2010 Crown Copyright. https://www.gov.uk/government/statistics/ english-indices-of-deprivation-2010. Accessed 17 July 2015

14. Bradshaw J, Bloor K, Huby M, Rhodes D, Sinclair I, Gibbs I (2009) Local index of child well-being: summary report. Crown Copyright, London

15. Laurens KR, Hobbs MJ, Sunderland M, Green MJ, Mould GL (2012) Psychotic-like experiences in a community sample of 
8000 children aged 9 to 11 years: an item response theory analysis. Psychol Med 42(7):1495-1506. doi:10.1017/ S0033291711002108

16. Kirkbride JB, Fearon P, Morgan C, Dazzan P, Morgan K, Murray RM, Jones PB (2007) Neighbourhood variation in the incidence of psychotic disorders in Southeast London. Soc Psychiatry Psychiatr Epidemiol 42(6):438-445. doi:10.1007/ s00127-007-0193-0

17. Laurens KR, West SA, Murray RM, Hodgins S (2008) Psychotic-like experiences and other antecedents of schizophrenia in children aged 9-12 years: a comparison of ethnic and migrant groups in the United Kingdom. Psychol Med 38(8):1103-1111. doi:10.1017/S0033291707001845

18. Coid JW, Kirkbride JB, Barker D, Cowden F, Stamps R, Yang M, Jones PB (2008) Raised incidence rates of all psychoses among migrant groups: findings from the East London first episode psychosis study. Arch Gen Psychiatry 65(11): 1250-1258. doi:10.1001/archpsyc.65.11.1250

19. Fearon P, Kirkbride JB, Morgan C, Dazzan P, Morgan K, Lloyd T, Hutchinson G, Tarrant J, Fung WL, Holloway J, Mallett R, Harrison G, Leff J, Jones PB, Murray RM, Group AS (2006) Incidence of schizophrenia and other psychoses in ethnic minority groups: results from the MRC AESOP study. Psychol Med 36(11):1541-1550. doi:10.1017/S0033291706008774

20. Costello A, Edelbrock C, Kalas R, Kessler M, Klaric S (1982) NIMH diagnostic interview schedule for children (DISC). National Institute of Mental Health, Rockville

21. Kelleher I, Connor D, Clarke MC, Devlin N, Harley M, Cannon M (2012) Prevalence of psychotic symptoms in childhood and adolescence: a systematic review and meta-analysis of population-based studies. Psychol Med 42(9):1857-1863. doi:10.1017/ S0033291711002960

22. van Os J, Linscott RJ, Myin-Germeys I, Delespaul P, Krabbendam L (2009) A systematic review and meta-analysis of the psychosis continuum: evidence for a psychosis pronenesspersistence-impairment model of psychotic disorder. Psychol Med 39(2):179-195. doi:10.1017/S0033291708003814

23. Linscott RJ, van Os J (2013) An updated and conservative systematic review and meta-analysis of epidemiological evidence on psychotic experiences in children and adults: on the pathway from proneness to persistence to dimensional expression across mental disorders. Psychol Med 43(6):1133-1149. doi:10.1017/S0033291712001626

24. Kelleher I, Harley M, Murtagh A, Cannon M (2011) Are screening instruments valid for psychotic-like experiences? A validation study of screening questions for psychotic-like experiences using in-depth clinical interview. Schizophr Bull 37(2):362-369. doi:10.1093/schbul/sbp057

25. Welham J, Scott J, Williams G, Najman J, Bor W, O'Callaghan M, McGrath J (2009) Emotional and behavioural antecedents of young adults who screen positive for non-affective psychosis: a 21-year birth cohort study. Psychol Med 39(4):625-634. doi:10. 1017/S0033291708003760

26. Markon KE (2010) Modeling psychopathology structure: a symptom-level analysis of axis I and II disorders. Psychol Med 40(2):273-288. doi:10.1017/S0033291709990183

27. Downs JM, Cullen AE, Barragan M, Laurens KR (2013) Persisting psychotic-like experiences are associated with both externalising and internalising psychopathology in a longitudinal general population child cohort. Schizophr Res 144(1-3):99-104. doi:10.1016/j.schres.2012.12.009

28. Lancefield KS, Raudino A, Downs JM, Laurens KR (in press) Trajectories of childhood internalizing and externalizing psychopathology and psychotic-like experiences in adolescence: a prospective population-based cohort study. Dev Psychopathol. doi:10.1017/S0954579415001108
29. Niemi LT, Suvisaari JM, Tuulio-Henriksson A, Lonnqvist JK (2003) Childhood developmental abnormalities in schizophrenia: evidence from high-risk studies. Schizophr Res 60(2-3): 239-258

30. Matheson SL, Vijayan H, Dickson H, Shepherd AM, Carr VJ, Laurens KR (2013) Systematic meta-analysis of childhood social withdrawal in schizophrenia, and comparison with data from at-risk children aged 9-14 years. J Psychiatr Res 47(8):1061-1068. doi:10.1016/j.jpsychires.2013.03.013

31. Myin-Germeys I, van Os J (2007) Stress-reactivity in psychosis: evidence for an affective pathway to psychosis. Clin Psychol Rev 27(4):409-424. doi:10.1016/j.cpr.2006.09.005

32. Phillips LJ, Francey SM, Edwards J, McMurray N (2007) Stress and psychosis: towards the development of new models of investigation. Clin Psychol Rev 27(3):307-317. doi:10.1016/j. cpr.2006.10.003

33. Varese F, Smeets F, Drukker M, Lieverse R, Lataster T, Viechtbauer W, Read J, van Os J, Bentall RP (2012) Childhood adversities increase the risk of psychosis: a meta-analysis of patient-control, prospective- and cross-sectional cohort studies. Schizophr Bull 38(4):661-671. doi:10.1093/schbul/sbs050

34. Cullen AE, Fisher HL, Roberts RE, Pariante CM, Laurens KR (2014) Daily stressors and negative life events in children at elevated risk of developing schizophrenia. $\mathrm{Br} \mathrm{J}$ Psychiatry 204:354-360. doi:10.1192/bjp.bp.113.127001

35. Cullen AE, Day FL, Roberts RE, Pariante CM, Laurens KR (2015) Pituitary gland volume and psychosocial stress among children at elevated risk for schizophrenia. Psychol Med. doi:10. 1017/S0033291715001282

36. Matheson SL, Shepherd AM, Pinchbeck RM, Laurens KR, Carr VJ (2013) Childhood adversity in schizophrenia: a systematic meta-analysis. Psychol Med 43(2):225-238. doi:10.1017/ S0033291712000785

37. Dickson H, Laurens KR, Cullen AE, Hodgins S (2012) Metaanalyses of cognitive and motor function in youth aged 16 years and younger who subsequently develop schizophrenia. Psychol Med 42(4):743-755. doi:10.1017/S0033291711001693

38. Khandaker GM, Barnett JH, White IR, Jones PB (2011) A quantitative meta-analysis of population-based studies of premorbid intelligence and schizophrenia. Schizophr Res 132(2-3):220-227. doi:10.1016/j.schres.2011.06.017

39. Cullen AE, Dickson H, West SA, Morris RG, Mould GL, Hodgins S, Murray RM, Laurens KR (2010) Neurocognitive performance in children aged 9-12 years who present putative antecedents of schizophrenia. Schizophr Res 121(1-3):15-23. doi:10.1016/j.schres.2010.05.034

40. Mesholam-Gately RI, Giuliano AJ, Goff KP, Faraone SV, Seidman LJ (2009) Neurocognition in first-episode schizophrenia: a meta-analytic review. Neuropsychology 23(3):315-336. doi:10. 1037/a0014708

41. Fusar-Poli P, Deste G, Smieskova R, Barlati S, Yung AR, Howes O, Stieglitz RD, Vita A, McGuire P, Borgwardt S (2012) Cognitive functioning in prodromal psychosis: a meta-analysis. Arch Gen Psychiatry 69(6):562-571. doi:10.1001/arch genpsychiatry.2011.1592

42. Giuliano AJ, Li H, Mesholam-Gately RI, Sorenson SM, Woodberry KA, Seidman LJ (2012) Neurocognition in the psychosis risk syndrome: a quantitative and qualitative review. Curr Pharm Des 18(4):399-415

43. Dickson H, Cullen AE, Reichenberg A, Hodgins S, Campbell DD, Morris RG, Laurens KR (2014) Cognitive impairment among children at-risk for schizophrenia. J Psychiatr Res 50:92-99. doi:10.1016/j.jpsychires.2013.12.003

44. Dickson H, Cullen AE, Jones R, Reichenberg A, Roberts RE, Hodgins S, Morris RG, Laurens KR (2014) Trajectories of cognitive development during adolescence in youth at-risk for 
schizophrenia. In: British psychological society developmental section annual conference, Amsterdam, Netherlands

45. Bora E, Lin A, Wood SJ, Yung AR, McGorry PD, Pantelis C (2014) Cognitive deficits in youth with familial and clinical high risk to psychosis: a systematic review and meta-analysis. Acta Psychiatr Scand 130(1):1-15. doi:10.1111/acps.12261

46. Kohler CG, Walker JB, Martin EA, Healey KM, Moberg PJ (2010) Facial emotion perception in schizophrenia: a meta-analytic review. Schizophr Bull 36(5):1009-1019. doi:10.1093/ schbul/sbn192

47. Thompson AD, Bartholomeusz C, Yung AR (2011) Social cognition deficits and the 'ultra high risk' for psychosis population: a review of literature. Early Interv Psychiatry 5(3):192-202. doi:10.1111/j.1751-7893.2011.00275.x

48. Dickson H, Calkins ME, Kohler CG, Hodgins S, Laurens KR (2014) Misperceptions of facial emotions among youth aged 9-14 years who present multiple antecedents of schizophrenia. Schizophr Bull 40(2):460-468. doi:10.1093/schbul/sbs193

49. Kohler CG, Richard JA, Brensinger CM, Borgmann-Winter KE, Conroy CG, Moberg PJ, Gur RC, Gur RE, Calkins ME (2014) Facial emotion perception differs in young persons at genetic and clinical high-risk for psychosis. Psychiatry Res 216(2):206-212. doi:10.1016/j.psychres.2014.01.023

50. Woods SW, Addington J, Bearden CE, Cadenhead KS, Cannon TD, Cornblatt BA, Mathalon DH, Perkins DO, Seidman LJ, Tsuang MT, Walker EF, McGlashan TH (2013) Psychotropic medication use in youth at high risk for psychosis: comparison of baseline data from two research cohorts 1998-2005 and 2008-2011. Schizophr Res 148(1-3):99-104. doi:10.1016/j. schres.2013.05.019

51. Shepherd AM, Laurens KR, Matheson SL, Carr VJ, Green MJ (2012) Systematic meta-review and quality assessment of the structural brain alterations in schizophrenia. Neurosci Biobehav Rev 36(4):1342-1356. doi:10.1016/j.neubiorev.2011.12.015

52. Cullen AE, De Brito SA, Gregory SL, Murray RM, Williams SC, Hodgins S, Laurens KR (2013) Temporal lobe volume abnormalities precede the prodrome: a study of children presenting antecedents of schizophrenia. Schizophr Bull 39(6): 1318-1327. doi:10.1093/schbul/sbs128

53. Laurens KR, Hodgins S, Mould GL, West SA, Schoenberg PL, Murray RM, Taylor EA (2010) Error-related processing dysfunction in children aged 9 to 12 years presenting putative antecedents of schizophrenia. Biol Psychiatry 67(3):238-245. doi:10.1016/j.biopsych.2009.07.030

54. Holroyd CB, Coles MG (2002) The neural basis of human error processing: reinforcement learning, dopamine, and the errorrelated negativity. Psychol Rev 109(4):679-709

55. Bruggemann JM, Stockill HV, Lenroot RK, Laurens KR (2013) Mismatch negativity (MMN) and sensory auditory processing in children aged 9-12 years presenting with putative antecedents of schizophrenia. Int J Psychophysiol 89(3):374-380. doi:10. 1016/j.ijpsycho.2013.05.008

56. Macmanus D, Laurens KR, Walker EF, Brasfield JL, Riaz M, Hodgins S (2012) Movement abnormalities and psychotic-like experiences in childhood: markers of developing schizophrenia? Psychol Med 42(1):99-109. doi:10.1017/S0033291711001085

57. Rosso IM, Bearden CE, Hollister JM, Gasperoni TL, Sanchez LE, Hadley T, Cannon TD (2000) Childhood neuromotor dysfunction in schizophrenia patients and their unaffected siblings: a prospective cohort study. Schizophr Bull 26(2):367-378

58. Walker EF, Savoie T, Davis D (1994) Neuromotor precursors of schizophrenia. Schizophr Bull 20(3):441-451

59. Mittal VA, Dhruv S, Tessner KD, Walder DJ, Walker EF (2007) The relations among putative biorisk markers in schizotypal adolescents: minor physical anomalies, movement abnormalities, and salivary cortisol. Biol Psychiatry 61(10):1179-1186. doi:10.1016/j.biopsych.2006.08.043

60. Aiello G, Horowitz M, Hepgul N, Pariante CM, Mondelli V (2012) Stress abnormalities in individuals at risk for psychosis: a review of studies in subjects with familial risk or with "at risk" mental state. Psychoneuroendocrinology 37(10):1600-1613. doi:10.1016/j.psyneuen.2012.05.003

61. Borges S, Gayer-Anderson C, Mondelli V (2013) A systematic review of the activity of the hypothalamic-pituitary-adrenal axis in first episode psychosis. Psychoneuroendocrinology 38(5):603-611. doi:10.1016/j.psyneuen.2012.12.025

62. Nordholm D, Krogh J, Mondelli V, Dazzan P, Pariante C, Nordentoft M (2013) Pituitary gland volume in patients with schizophrenia, subjects at ultra high-risk of developing psychosis and healthy controls: a systematic review and metaanalysis. Psychoneuroendocrinology 38(11):2394-2404. doi:10. 1016/j.psyneuen.2013.06.030

63. Shah JL, Malla AK (2015) Much ado about much: stress, dynamic biomarkers and HPA axis dysregulation along the trajectory to psychosis. Schizophr Res 162(1-3):253-260. doi:10.1016/j.schres.2015.01.010

64. Walker E, Mittal V, Tessner K (2008) Stress and the hypothalamic pituitary adrenal axis in the developmental course of schizophrenia. Annu Rev Clin Psychol 4:189-216. doi:10.1146/ annurev.clinpsy.4.022007.141248

65. Walker EF, Diforio D (1997) Schizophrenia: a neural diathesisstress model. Psychol Rev 104(4):667-685

66. Buschlen J, Berger GE, Borgwardt SJ, Aston J, Gschwandtner U, Pflueger MO, Kuster P, Radu EW, Stieglitz RD, RiecherRossler A (2011) Pituitary volume increase during emerging psychosis. Schizophr Res 125(1):41-48. doi:10.1016/j.schres. 2010.09.022

67. Pariante CM, Dazzan P, Danese A, Morgan KD, Brudaglio F, Morgan C, Fearon P, Orr K, Hutchinson G, Pantelis C, Velakoulis D, Jones PB, Leff J, Murray RM (2005) Increased pituitary volume in antipsychotic-free and antipsychotic-treated patients of the AEsop first-onset psychosis study. Neuropsychopharmacol 30(10):1923-1931. doi:10.1038/sj.npp.1300766

68. Pariante CM, Vassilopoulou K, Velakoulis D, Phillips L, Soulsby B, Wood SJ, Brewer W, Smith DJ, Dazzan P, Yung AR, Zervas IM, Christodoulou GN, Murray R, McGorry PD, Pantelis C (2004) Pituitary volume in psychosis. Br J Psychiatry 185:5-10

69. Takahashi T, Nakamura K, Nishiyama S, Furuichi A, Ikeda E, Kido M, Nakamura Y, Kawasaki Y, Noguchi K, Seto H, Suzuki M (2013) Increased pituitary volume in subjects at risk for psychosis and patients with first-episode schizophrenia. Psychiatry Clin Neurosci 67(7):540-548. doi:10.1111/pcn.12093

70. Takahashi T, Zhou SY, Nakamura K, Tanino R, Furuichi A, Kido M, Kawasaki Y, Noguchi K, Seto H, Kurachi M, Suzuki M (2011) Longitudinal volume changes of the pituitary gland in patients with schizotypal disorder and first-episode schizophrenia. Prog Neuropsychopharmacol Biol Psychiatry 35(1):177-183. doi:10.1016/j.pnpbp.2010.10.023

71. Ford T, Hamilton H, Meltzer H, Goodman R (2007) Child mental health is everybody's business: the prevalence of contact with public sector services by type of disorder among British school children in a three-year period. Child Adolesc Mental Health 12(1):13-20. doi:10.1111/j.1475-3588.2006. 00414.x

72. Lawrence D, Johnson S, Hafekost J, Boterhoven de Haan K, Sawyer M, Ainley J, Zubrick SR (2015) The mental health of children and adolescents. Report on the second Australian child and adolescent survey of mental health and wellbeing. Commonwealth of Australia, Department of Health, Canberra 
73. Gronholm PC, Ford T, Roberts RE, Thornicroft G, Laurens KR, Evans-Lacko S (2015) Mental health service use by young people: the role of caregiver characteristics. PLoS One 10(3):e0120004. doi:10.1371/journal.pone.0120004

74. Maddox L, Jolley S, Laurens KR, Hirsch C, Hodgins S, Browning S, Bravery L, Bracegirdle K, Smith P, Kuipers E (2013) Cognitive behavioural therapy for unusual experiences in children: a case series. Behav Cognit Psychother 41(3):344-358. doi:10.1017/S1352465812000343

75. Ames CS, Jolley S, Laurens KR, Maddox L, Corrigall R, Browning S, Hirsch CR, Hassanali N, Bracegirdle K, Kuipers E (2014) Modelling psychosocial influences on the distress and impairment caused by psychotic-like experiences in children and adolescents. Eur Child Adolesc Psychiatry 23(8):715-722. doi:10.1007/s00787-013-0500-0

76. Noone D, Ames C, Hassanali N, Browning S, Bracegirdle K, Corrigall R, Laurens KR, Hirsch CR, Kuipers E, Maddox L, Fowler D, Jolley S (2015) A preliminary investigation of schematic beliefs and unusual experiences in children. Eur Psychiatry 30(5):569-575. doi:10.1016/j.eurpsy.2014.12.006

77. Anilmis JA, Stewart CS, Roddy S, Hassanali N, Muccio F, Browning S, Bracegirdle K, Corrigal R, Laurens KR, Hirsch C, Kuipers E, Maddox L, Jolley S (2015) Understanding the relationship between schematic beliefs, bullying, and unusual experiences in 8-14 year olds. Eur Psychiatry 30(8):920-923. doi:10.1016/j.eurpsy.2015.08.008

78. Ruffell T, Azis M, Hassanali N, Ames C, Browning S, Bracegirdle K, Corrigall R, Laurens KR, Hirsch C, Kuipers E, Maddox L, Jolley S (2015) Variation in psychosocial influences according to the dimensions and content of children's unusual experiences: potential routes for the development of targeted interventions. Eur Child Adolesc Psychiatry. doi:10.1007/ s00787-015-0739-8

79. Howes OD, Murray RM (2014) Schizophrenia: an integrated sociodevelopmental-cognitive model. Lancet 383(9929):1677-1687. doi:10.1016/S0140-6736(13)62036-X

80. Agnew-Blais J, Seidman LJ (2013) Neurocognition in youth and young adults under age 30 at familial risk for schizophrenia: a quantitative and qualitative review. Cognitive Neuropsychiatry 18(1-2):44-82. doi:10.1080/13546805.2012.676309

81. Sitskoorn MM, Aleman A, Ebisch SJ, Appels MC, Kahn RS (2004) Cognitive deficits in relatives of patients with schizophrenia: a meta-analysis. Schizophr Res 71(2-3):285-295. doi:10.1016/j.schres.2004.03.007

82. Tarbox SI, Pogue-Geile MF (2008) Development of social functioning in preschizophrenia children and adolescents: a systematic review. Psychol Bull 134(4):561-583. doi:10.1037/ 0033-2909.34.4.561

83. Cannon TD (2005) Clinical and genetic high-risk strategies in understanding vulnerability to psychosis. Schizophr Res 79(1):35-44. doi:10.1016/j.schres.2005.06.014

84. Schimmelmann BG, Walger P, Schultze-Lutter F (2013) The significance of at-risk symptoms for psychosis in children and adolescents. Can J Psychiatry 58(1):32-40

85. Polier GG, Vloet TD, Herpertz-Dahlmann B, Laurens KR, Hodgins S (2012) Comorbidity of conduct disorder symptoms and internalising problems in children: investigating a community and a clinical sample. Eur Child Adolesc Psychiatry 21(1):31-38. doi:10.1007/s00787-011-0229-6

86. Goodman R (2001) Psychometric properties of the strengths and difficulties questionnaire. J Am Acad Child Adolesc Psychiatry 40(11):1337-1345

87. Kaufman J, Birmaher B, Brent D, Rao N, Ryan N (1997) The schedule for affective disorders and schizophrenia for school aged children: present and lifetime version. University of Pittsburgh, Western Psychiatric Institute and Clinic, Pittsburgh
88. Achenbach TM, Rescorla LA (2001) Manual for the ASEBA school-age forms and profiles. University of Vermont, Research Center for Children, Youth, \& Families, Burlington

89. Reynolds CR, Richmond BO (2008) Revised children's manifest anxiety scale, second edition (RCMAS-2) manual. Western Psychological Services, Los Angeles

90. Beck JS, Beck AT, Jolly JB, Steer RA (2005) Beck youth inventories second edition for children and adolescents manual (depression inventory for youth). Harcourt Assessment, Inc. (PsychCorp), San Antonio

91. Frick PJ, Hare RD (2001) Antisocial process screening device: technical manual. Multi-Health Systems Inc., Toronto

92. Rutter M, Bailey A, Lord C (2003) SCQ - the social communication questionnaire manual. Western Psychological Services, Los Angeles

93. Loewy RL, Pearson R, Vinogradov S, Bearden CE, Cannon TD (2011) Psychosis risk screening with the prodromal questionnaire-brief version (PQ-B). Schizophr Res 129(1):42-46. doi:10.1016/j.schres.2011.03.029

94. Yung AR, Yuen HP, McGorry PD, Phillips LJ, Kelly D, Dell'Olio M, Francey SM, Cosgrave EM, Killackey E, Stanford C, Godfrey K, Buckby J (2005) Mapping the onset of psychosis: the comprehensive assessment of at-risk mental states. Aust N Z J Psychiatry 39(11-12):964-971. doi:10.1111/j.1440-1614. 2005.01714.x

95. John OP, Srivastava S (2001) The big five trait taxonomy: history, measurement, and theoretical perspectives. In: Pervin LA, John OP (eds) Handbook of personality: theory and research, 2nd edn. Guilford Press, New York, pp 102-138

96. Hall RC (1995) Global assessment of functioning. A modified scale. Psychosomatics 36(3):267-275. doi:10.1016/S00333182(95)71666-8

97. Maxwell ME (1992) Family interview for genetic studies. Clinical neurogenetics branch, intramural research program. National Institute of Mental Health, St. Louis

98. Shelton KK, Frick PJ, Wootton JM (1996) Assessment of parenting practices in families of elementary school-age children. J Clin Child Psychol 25(3):317-329

99. Epstein NB, Bishop DS, Levin D (2005) Family assessment device, version 3L: instructions on how to score the FAD, FAD scoring McMaster model dimensions, family assessment device-general functioning scale. In: Ryan CE, Epstein NB, Keitner GI, Miller IW, Bishop DS (eds) Evaluating and treating families: the McMaster approach. Routledge, New York

100. Caspi A, Moffitt TE, Morgan J, Rutter M, Taylor A, Arseneault L, Tully L, Jacobs C, Kim-Cohen J, Polo-Tomas M (2004) Maternal expressed emotion predicts children's antisocial behavior problems: using monozygotic-twin differences to identify environmental effects on behavioral development. Dev Psychol 40(2):149-161. doi:10.1037/0012-1649.40.2.149

101. Magana AB, Goldstein JM, Karno M, Miklowitz DJ, Jenkins J, Falloon IR (1986) A brief method for assessing expressed emotion in relatives of psychiatric patients. Psychiatry Res 17(3):203-212

102. McVie S, Bradshaw P (2005) Adolescent smoking, drinking and drug use. Number 7. The Edinburgh study of youth transitions and crime. Centre for Law and Society, The University of Edinburgh, Edinburgh

103. Heubeck B, O'Sullivan C (1998) An exploration into the nature, frequency and impact of school hassles in the middle school years. Aust Psychol 33(2):130-137

104. Brugha TS, Cragg D (1990) The list of threatening experiences: the reliability and validity of a brief life events questionnaire. Acta Psychiatr Scand 82(1):77-81

105. Cohen S, Kamarck T, Mermelstein R (1983) A global measure of perceived stress. J Health Soc Behav 24(4):385-396 
106. Bernstein DP, Fink L (1998) Childhood trauma questionnaire: a retrospective self-report manual. The Psychological Corporation, San Antonio

107. Finkelhor D, Hamby S, Turner H, Ormrod R (2011) The juvenile victimization questionnaire: 2 nd revision (JVQ-R2). Crimes Against Children Research Center, Durham

108. Moran P, Coffey C, Romaniuk H, Olsson C, Borschmann R, Carlin JB, Patton GC (2012) The natural history of self-harm from adolescence to young adulthood: a population-based cohort study. Lancet 379(9812):236-243. doi:10.1016/S0140-6736(11)61141-0

109. Schonert-Reichl KA, Guhn M, Hymel S, Hertzman C, Sweiss L, Gadermann A, Marriott D, Burroughs B, Calbick J, Oberle E, Smith A, Pedrini L, Harvey J (2010) Our children's voices-the middle years development instrument: measuring the developmental health and well-being of children in middle childhood. United Way, Vancouver

110. Office for National Statistics (2010) The national statistics socio-economic classification. National Statistics, Fareham

111. Carskadon MA, Acebo C (1993) A self-administered rating scale for pubertal development. J Adolesc Health 14(3):190-195

112. Annett M (1970) A classification of hand preference by association analysis. Br J Psychol 61(3):303-321

113. Oldfield RC (1971) The assessment and analysis of handedness: the Edinburgh inventory. Neuropsychologia 9(1):97-113

114. Coren S (1993) The lateral preference inventory for measurement of handedness, footedness, eyedness, and earedness: norms for young adults. Bull Psychonom Soc 31(1):103

115. Tiffin J (1948) Purdue pegboard test: user manual. Lafayette Instrument, Lafayette

116. Mittal VA, Neumann C, Saczawa M, Walker EF (2008) Longitudinal progression of movement abnormalities in relation to psychotic symptoms in adolescents at high risk of schizophrenia. Arch Gen Psychiatry 65(2):165-171. doi:10.1001/arch genpsychiatry.2007.23

117. Wechsler D (1999) Wechsler abbreviated scale of intelligence (WASI) manual. Psychological Corporation, San Antonio

118. Wechsler D (2005) The Wechsler individual achievement test, 2nd edn. Pearson Assessment, London

119. Smith A (1982) Symbol digit modalities test manual. Western Psychological Services, Los Angeles

120. Sheslow D, Adams W (2003) Wide range assessment of memory and learning - second edition (WRAML2). Wide range Inc, Delaware

121. Delis DC, Kaplan E, Kramer JH (2001) The Delis-Kaplan executive function system: examiners manual. The Psychological Corporation, San Antonio

122. Erwin RJ, Gur RC, Gur RE, Skolnick B, Mawhinney-Hee M, Smailis J (1992) Facial emotion discrimination: I. Task construction and behavioral findings in normal subjects. Psychiatry Res 42(3):231-240
123. Kohler CG, Anselmo-Gallagher G, Bilker W, Karlawish J, Gur RE, Clark CM (2005) Emotion-discrimination deficits in mild Alzheimer disease. Am J Geriatr Psychiatry 13(11):926-933. doi:10.1176/appi.ajgp.13.11.926

124. Callicott JH, Egan MF, Mattay VS, Bertolino A, Bone AD, Verchinksi B, Weinberger DR (2003) Abnormal fMRI response of the dorsolateral prefrontal cortex in cognitively intact siblings of patients with schizophrenia. Am J Psychiatry 160(4):709-719

125. Laurens KR, Kiehl KA, Ngan ET, Liddle PF (2005) Attention orienting dysfunction during salient novel stimulus processing in schizophrenia. Schizophr Res 75(2-3):159-171. doi:10.1016/j. schres.2004.12.010

126. Rubia K, Smith AB, Brammer MJ, Taylor E (2003) Right inferior prefrontal cortex mediates response inhibition while mesial prefrontal cortex is responsible for error detection. NeuroImage 20(1):351-358

127. Horwitz SM, Hoagwood K, Stiffman AR, Summerfeld T, Weisz JR, Costello EJ, Rost K, Bean DL, Cottler L, Leaf PJ, Roper M, Norquist G (2001) Reliability of the services assessment for children and adolescents. Psychiatr Serv 52(8):1088-1094

128. Webber MP, Huxley PJ (2007) Measuring access to social capital: the validity and reliability of the resource generator-UK and its association with common mental disorder. Soc Sci Med 65(3):481-492. doi:10.1016/j.socscimed.2007.03.030

129. Sampson RJ, Raudenbush SW, Earls F (1997) Neighborhoods and violent crime: a multilevel study of collective efficacy. Science 277(5328):918-924

130. Starfield B, Bergner M, Ensminger M, Riley A, Ryan S, Green B, McGauhey P, Skinner A, Kim S (1993) Adolescent health status measurement: development of the child health and illness profile. Pediatrics 91(2):430-435

131. Jorm AF, Wright A, Morgan AJ (2007) Where to seek help for a mental disorder? National survey of the beliefs of Australian youth and their parents. Med J Aust 187(10):556-560

132. Schomerus G, Auer C, Rhode D, Luppa M, Freyberger HJ, Schmidt S (2012) Personal stigma, problem appraisal and perceived need for professional help in currently untreated depressed persons. J Affect Disord 139(1):94-97. doi:10.1016/j. jad.2012.02.022

133. Evans-Lacko S, Rose D, Little K, Flach C, Rhydderch D, Henderson C, Thornicroft G (2011) Development and psychometric properties of the reported and intended behaviour scale (RIBS): a stigma-related behaviour measure. Epidemiol Psychiatr Sci 20(3):263-271

134. Rusch N, Corrigan PW, Wassel A, Michaels P, Olschewski M, Wilkniss S, Batia K (2009) A stress-coping model of mental illness stigma: I. Predictors of cognitive stress appraisal. Schizophr Res 110(1-3):59-64. doi:10.1016/j.schres.2009.01.006 